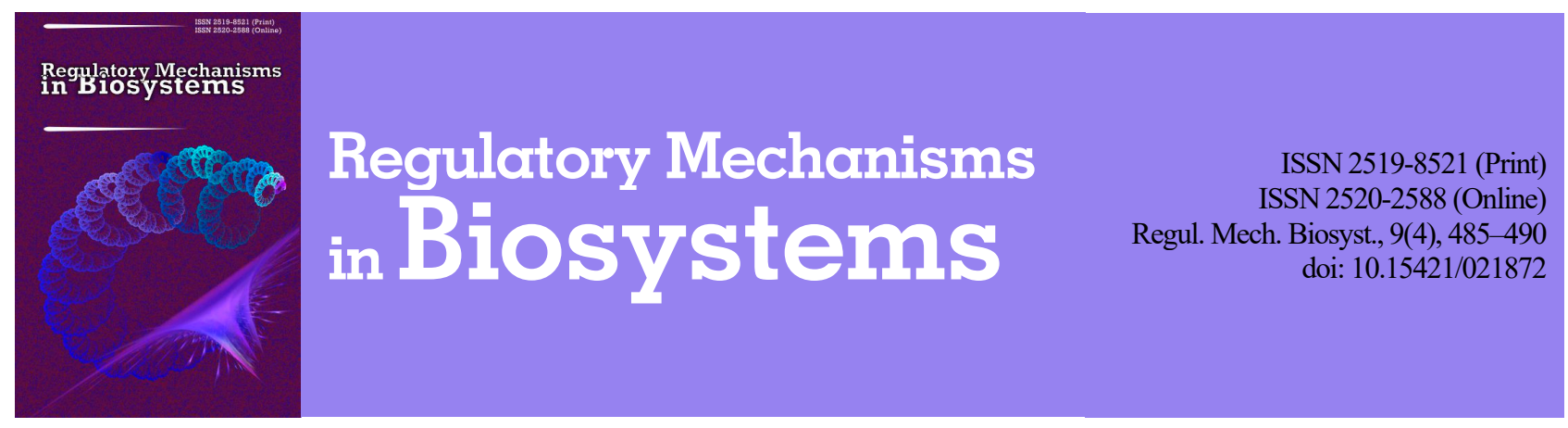

\title{
Non-invasive evaluation of cerebral hemodynamic and intracranial pressure in pediatric neuroinfections
}

\author{
M. A. Georgiynts*, V. A. Korsunov*, O. M. Olkhovska**, K. E. Stoliarov*** \\ *Kharkiv Medical Academy of Postgraduate Education, Kharkiv, Ukraine \\ **Kharkiv National Medical University, Kharkiv, Ukraine \\ ***Kharkiv Regional Pediatric Infection Clinical Hospital, Kharkiv, Ukraine
}

Article info

Received 12.09.2018

Received in revised form 20.10.2018

Accepted 23.10.2018

Kharkiv Medical Academy of Postgraduate Education, Amosova st., 58 ,

Kharkiv, 61167, Ukraine.

Tel.: +38-057-974-41-81.

E-mail:office@med.edu.ua

Kharkiv National Medical University, Nauki av., 4 Kharkiv, 61022, Ukraine. Tel.: +38-057-297-21-32.

E-mail:diknmu@gmail.com

Kharkiv Regional Pediatric Infection Clinical Hospital, Heroyv Stalingradu av., 160, Kharkiv, 61067, Ukraine. Tel.: +38-057-297-61-55. E-mail: odikl2018@ukr.net

Introduction

Infection of the central nervous system in children is a relevant problem for intensive care due to the high incidence of urgent conditions and disorders of vital functions. Structural and functional lesions of the central nervous system caused by neuroinfection can cause disturbances of consciousness, critical intracranial hypertension, urethral syndromes (syndromes of obstruction) and failure of autonomous regulation of vital functions, which in turn is a factor in the onset of fatal outcomes or neurological deficiency (Becman \& Tyler, 2012). Thus, according to foreign reviews, over a 12 -year observation period, the mortality rate of $11.8 \%$ patients in pediatric intensive care units with neuroinfection is reported (Hon et al., 2016). Critical intracranial hypertension, which occurs as a result of cerebral edema, intracranial hemo- and lymphoid dynamics disorders, is the most significant predictor of disorder of vital functions (Lan et al., 2016). Increased intracranial pressure (ICP) or intracranial hypertension is a widespread neurological complication in children with critical conditions (Hovart et al., 2016). The universal effects of intracranial hypertension are the reduction of cerebral perfusion pressure (CPP), since $\mathrm{CPP}=\mathrm{MAP}-\mathrm{ICP}$, where MAP is mean arterial pressure, as well as cerebral ischemia and adhesion syndromes that cause secondary intensive care and evaluating its effectiveness. \author{
hemodynamic and intracranial pressure in pediatric neuroinfections. Regulatory Mechanisms in Biosystems, $9(4), 485-490$. \\ doi:10.15421/021872
}

The study of intracranial pressure (eICP), cerebral perfusion pressure (eCPP), cerebral blood flow index (CFI), zero flow pressure, and cardiac output), pulse oximetry, capnography, hemoglobin, hematocr prein, urea, creatinine, lactate, glucose and serum electrolytes was done. An ultrasound scanner was used to perform ultrasound divided into group I with RI $>1.3$ and group II with RI $<13$. It was found that eCPP in the group I was sionificantly 1 ess $(29.5+$ $\mathrm{I}$, the difference in eCPP was found due to a significant difference in eICP $-34.6 \pm 1.4$ and $27.6 \pm 0.89 \mathrm{~mm} \mathrm{Hg}$ in I and II groups and eSRP and CFI, presumably associated with a loss of autoregulation. CFI in the group I was lower than in the group II. Thus, nonexamination of cerebral flow in MCA by duplex sonography revealed that PI $>1.3$ is an informative marker of intracranial

Keywords: cerebral perfusion pressure; transcranial Doppler sonography; critical care; children; central nervous system; infection neurological outcomes (Shein et al., 2016). ICP growth to $20-25 \mathrm{~mm} \mathrm{Hg}$ requires intensive care (Hovart et al., 2016; Shein et al., 2016). Meanwhile, there are significant problems with the determination of ICP in children with non-surgical pathology of the central nervous system, since the standard ICP evaluation method is invasive and is carried out by determining an intraventricular or subdural catheter directly during neurosurgical intervention. Thus, in children with non-surgical causes of intracranial hypertension, the definition of ICP is often impossible, and therefore, intensive care is based on the assessment of only clinical symptoms. At the same time, in contrast to the intensive therapy of neurotrau$\mathrm{ma}$, there are certain controversies regarding intensive neuroinfection therapy regarding the feasibility of using ICP monitoring, as the 2006 issue of the Pediatrics Journal revealed the results of a retrospective cohort study of ICP monitoring in meningitis in intensive care units in the United States. The study included children aged 0 to 17 years with severe meningitis who needed respiratory support, of which $80 \%$ were children under 1 year old. The researchers found no significant differences in mortality between the cohort of patients who were monitored by ICP and the cohort of patients who received intensive care without monitoring by ICP. Hospital mortality was about $19 \%$ for both cohorts 
(Odetola et al., 2006). Meanwhile, there are other opinions, as evidence is provided that lowering ICP may reduce the mortality in patients with bacterial meningitis (Lindvall et al., 2004). A recent publication by $\mathrm{Ku}-$ mar et al. (2014) provides evidence that intensive therapy aimed at supporting CPP is more effective in children with neuroinfections than intensive therapy aimed at correcting ICP. In this study, children with neuroinfection were divided into groups with different intensive care target points. In one group, CPP was tried to maintain more than $60 \mathrm{~mm} \mathrm{Hg}$ due to infusion and sympathomimetics, in another - they tried to maintain ICP $<20 \mathrm{~mm} \mathrm{Hg}$ by using osmodiuretics. The mortality rate for 90 days in the ICP support group was $38.2 \%$, while in the CPP support group it was $18.2 \%(\mathrm{RR}=2.1 ; 95 \% \mathrm{CI}, 1.09-4.04 ; \mathrm{P}=0.020)$. In addition, in the CPP support group, consciousness was restored more quickly, respiratory support lasted for a shorter time, neurological deficit was less (Kumar et al., 2014). Consequently, the definition of ICP and CPP, their use as guidelines for purposeful intensive therapy of intracranial hypertension in patients with neuroinfection is a promising direction in modern medicine. However, it should be noted that these two doctrines, because of the impossibility of using invasive methods of control, require reliable non-invasive, sufficiently precise and specific methods for determining intracranial homeostasis. In addition, non-invasive methods for determining ICP and CPP, unlike invasive, differ considerably in the number of complications, are more convenient and safe to use (Asiedua et al., 2014). The most well known and relevant methods are ultrasound, among which transcranial dopplerography of the blood flow in the middle cerebral arteries (MCA) is used, which makes it possible to determine the resistance index of Pourcelot (RI), the Gosling-King pulsed index (PI). Many researchers have shown a close correlation between PI and ICP $(\mathrm{r}=$ $0.938, \mathrm{P}<0.0001$ ) (Sadoughiet al., 2013). Changes in PI by $2.4 \%$ correspond to an ICP change of $1 \mathrm{~mm} \mathrm{Hg}$. (Naqvi et al., 2013; Robba et al., 2018). Based on the calculations, additional information on eCPP - noninvasive $\mathrm{CPP}$, ICP - intracranial pressure, RAP index (correlation reservecorrelation coefficient $(\mathrm{R})$ between AMP amplitude (A) and mean pressure (P)), CFI - cerebral blood flow index, CCP (ZFP) - critical closing pressure (zero flow pressure) can be obtained (Edouard et al., 2005). Recently, a high correlation between invasive CPP and eCPP was demonstrated $(\mathrm{r}=0.851, \mathrm{P}<0.001)$ (Varsos et al., 2015). In patients with craniocerebral trauma, a non-invasive determination of ICP based on Doppler ultrasonography of PI measurement has the highest accuracy in comparison with other Doppler methods of ICP estimation (Cardim et al., 2016). Another study showed that the end-diastolic blood flow velocity of less than $25 \mathrm{~cm} / \mathrm{s}$ and PI more than 1.31 in transcranial Doppler sonography in children with traumatic brain injury had $94 \%$ sensitivity for predicting ICP greater than $20 \mathrm{mmHg}$ and a negative predictive value of $95 \%$ for normal ICP (O'Brien et al., 2015). Similar data were obtained by other authors who also show that in children with traumatic brain injury, an increase in RI greater than 1.3 is a highly sensitive and specific sign of an increase in ICP of more than $20 \mathrm{~mm} \mathrm{Hg}$. (LaRovere et al., 2015).

The first evaluation of ICP using transcranial Doppler sonography was proposed by Kligenchöfer et al. (1987), using the formula:

$$
I C P=\frac{R I+M A P}{\text { Vmean } C M A},
$$

which was modified by Trukhanov et al. (2014), as follows:

$$
I C P=\frac{R I+M A P}{\text { VmeanCMA }} \times 12+6,
$$

where MAP is mean arterial pressure (Kligenchöfer et al., 1988; Truhanov et al., 2014).

Later, Bellner et al. (2004) proposed the following formula for the determination of the ICP:

$$
I C P=10.93 \times P I-1.28 \text {. }
$$

Based on the assumption that the difference between the systolic and diastolic blood flow velocity in the MCA in a certain way reflects $\mathrm{CPP}$, in recent years a significant number of formulae have been proposed for noninvasive determination of cerebral perfusion pressure. For the first time in 1986. R. Aaslid et al. justified the formula:

$$
C P P=1.1 \times \frac{(\text { Vmean } C M A+B P 1)}{V 1}-5,
$$

where BP1 is the amplitude of the first harmonic of the pulse wave for the invasive determination of $\mathrm{BP}$, and $\mathrm{V} 1$ is the amplitude of the first harmonic of the MCA dopplerography in the M1 segment. To avoid invasive BP, the formula was transformed and it was as follows:

$$
C P P=1.1 \times \frac{(1.1 \times S B P \times V m e a n C M A)}{V \max C M A}-5,
$$

where SBP is systolic blood pressure (Aaslid et al., 1986). Bellner et al. (2004) on the basis of the regression equation, proposed the following formula for the determination of CPP:

$$
C P P=89.646-8.258 \times P I \text {. }
$$

Edouard et al. (2005) proved the high informativeness of the formula:

$$
C P P=\frac{V \text { mean } C M A}{[\text { Vmean } C M A-V \min C M A]} \times M B P-D B P .
$$

A comparative analysis of invasive and non-invasive ICP and CPP indices enabled Schmidt et al. (2001) to suggest the following formula for determining CPP:

$$
C P P=M B P \times \frac{V \min C M A}{V \text { mean } C M A}+14 .
$$

Recently, it has been believed that cerebral perfusion is more effectively characterized not by the CPP, but by an indicator of zero-flow pressure, the achievement of which stops blood flow in the vessels of the meninges. Based on the concept of zero pressure (ZFP) or critical closing pressure (CCP), which is characterized by arterial blood pressure at which the blood flow in brain vessels is stopped due to their compression from the outside, it is shown that ZFP $=\mathrm{ICP}+\mathrm{VT}$, where VT is an own vascular tone (Schmidt et al., 2001). Ogoh proposed the following formula (Ogoh, 2008; Varsos et al., 2015):

$\mathrm{CCP}(\mathrm{ZFP})=\mathrm{BPS}-(\mathrm{BPS}-\mathrm{BPD}) /\left(\mathrm{V}_{\max } \mathrm{CMA}-\mathrm{V}_{\min } \mathrm{CMA}\right) * \mathrm{~V}_{\max } \mathrm{CMA}$ or $\mathrm{ZFP}=\mathrm{MAP}-\mathrm{CPP}$.

The absolute majority of the studies analyzing the validity of the proposed methods for non-invasive determination of intracranial homeostasis parameters have been performed in neurosurgical patients with craniocerebral trauma, cerebral infarctions, hydrocephalus, etc. At the same time, in the sources available to us we have not found the studies on the status of cerebral homeostasis, blood flow, ICP and CPP in children with CNS infections using non-invasive Doppler techniques. Therefore, we set the goal of studying the state of circulation in the middle cerebral artery and the calculated indices of intracranial homeostasis in children with infections of the CNS that needed intensive therapy because of a disorder of consciousness and vital functions. Also, the aim of the study was to compare the results obtained by different methods of determining ICP and CPP.

\section{Materials and methods}

Over 2015-2018, me conducted a monitoring of 49 children with an average age of 70 months (Min - 1.5 months, Max - 214.0 months) with infections of the CNS (purulent and serous meningitis, encephalitis, subdural empyema, etc.), who were admitted to the Department of Anaesthesiology and Intensive Care of the Public Health Service Kharkiv Regional Children's Infectious Clinical Hospital . The etiological structure of the examined patients is presented in Table 1.

Table 1

Etiological structure of the examined patients

\begin{tabular}{lc}
\hline \multicolumn{1}{c}{ Nosology } & Number of patients \\
\hline Viral encephalitis & 21 \\
Purulent meningitis & 11 \\
Meningococcal infection, meningitis & 13 \\
Serous (aseptic) meningitis & 3 \\
Subdural empyema & 1 \\
& Total \\
\hline
\end{tabular}

Indications for hospitalization were disorders of consciousness, clinical signs of increased intracranial pressure, convulsions, respiratory distress and hemodynamics disorders. Nineteen children $(38.8 \%)$ needed of invasive respiratory support, which was carried out in accordance with the principles of pulmonary-protective ventilation and provided normocapnia $\left(\mathrm{pCO}_{2}-36-44 \mathrm{~mm} \mathrm{Hg}\right)$. Other patients underwent oxygen therapy. The level of consciousness disorder was determined by Glasgow's pediatric scale. The average score was 8.6 (Min - 4, Max - 15). Simultaneously with ensuring the stability of the vital functions, ECG monitoring, 
heart rate (HR), systolic (SBP), diastolic (DBP) and mean blood pressure (MBP) with the oscillometric method, pulse oximetry $\left(\mathrm{SpO}_{2}\right)$, capnography $\left(\mathrm{EtCO}_{2}\right)$, (monitor systems UM-300, Imec 8, Heaco) were carried out. After providing peripheral or central venous access, we determined hemoglobin, hematocrit, total protein, urea, creatinine, lactate, glucose (semi-automatic biochemical analyzer Stat Fax 1904+, USA) and serum electrolyte content $\left(\mathrm{Na}^{+}, \mathrm{K}^{+}, \mathrm{Cl}^{-}, \mathrm{Ca}^{+}\right)$using automatic analyzer (AEK-01 QuartyMed, Russia).

The state of the central hemodynamics was determined by the ultrasound method in the M-mode by measuring the end-diastolic (EDD) and end-systolic (ESD) diameter of the left ventricle (ultrasound scanner Ultima PA, Radmir, Ukraine). Based on the obtained data using Teichholz et al. (1976) formula we calculated the end-systolic (ESV) and end-diastolic volume (EDV) of the left ventricle, systolic volume (SV), end-diastolic index, (IEDV), systolic index (SI), ejection fraction (EF), cardiac output $(\mathrm{CO})$, cardiac index (CI), total peripheral vascular resistance index (IPVR).

$$
\begin{aligned}
& \text { Oxygen delivery }\left(\mathrm{DO}_{2}\right) \text { was determined by the formula: } \\
& \qquad \mathrm{DO} 2=\mathrm{CI} \times \mathrm{SaO} 2 \times \mathrm{Hb} .
\end{aligned}
$$

Ultrasound duplex scanning of blood flow in the right and left middle cerebral arteries (RMCA and LMCA) in the M1 segment by transtemporal access with automatic measurement of the maximum blood flow velocity $\left(\mathrm{V}_{\max }, \mathrm{cm} / \mathrm{s}\right)$ and the minimum blood flow velocity $\left(\mathrm{V}_{\min }, \mathrm{cm} / \mathrm{s}\right)$ was performed for all patients using a sensor with phased array $\mathrm{P}_{2-3 / 20}$ (frequency of 2-3 thousand $\mathrm{MHz}$ ).

The average blood flow velocity $\left(\mathrm{V}_{\text {mean }}, \mathrm{cm} / \mathrm{s}\right)$ was calculated by the formula:

$$
\text { Vmean }=\frac{V \max +2 \times V \min }{3} .
$$

The pulsating index Gosling (PI) was determined by the formula:

$$
P I=\frac{V \max -V \min }{\text { Vmean }}
$$

The index of resistance Pourselot $(\mathrm{RI})$ was identified by the formula:

$$
R I=\frac{V \max -V \min }{V \max } .
$$

All of these calculations were performed automatically by Ultima PA ultrasound scanner. Established (noninvasive) cerebral perfusion pressure (eCPP) was determined by the formula (Edouard et al., 2005):

$$
e C P P=\frac{V m e a n M C A}{[\text { VmeanMCA }-V \min M C A]} \times M B P-D A P .
$$

All other formulae (Aaslid et al., 1986; Schmitd et al., 2001; Bellner et al., 2004) contain constant coefficients obtained by regression. Consequently, they can independently influence the results of measured blood flow parameters, which, in our opinion, is capable of distorting the result.

The RAP index was calculated by the formula:

$$
R A P=\frac{M A P}{V m e a n C M A} \text {. }
$$

Cerebral flow index (CFI) was determined by the formula:

$$
C F I=\frac{e C P P}{R I} .
$$

The critical closing pressure (zero flow pressure) (CCP-ZFP) was calculated by the formula:

$$
C C P=e C P P-M B P .
$$

Intracranial pressure (eICP) was calculated by the formula:

$$
e I C P=M B P-e C P P \text {. }
$$

In addition, the eICP was determined by the formulae:

$$
\begin{aligned}
& \operatorname{eICP}(K)=\frac{R I+M B P}{V m e a n C M A} \text { and } \\
& \operatorname{eICP}(B)=10.93 \times P I-1.28 .
\end{aligned}
$$

All patients were divided into group I, which included patients with PI more than 1.3 , which, according to the literature data, is a highly specific and sensitive sign of an increase in ICP to $20 \mathrm{~mm} \mathrm{Hg}$, and group II - patients with PI less than 1.3. As its known, PI.

To analyze the obtained data, a database was created by the Statistica 10 program (StatSoft Inc., USA). Test of normality was carried out according to the criterion of Kolmogorov-Smirnov. Due to the fact that the distribution of signs was close to normal $(\mathrm{P}<0.05)$, the reliability of the differences between the groups at $\mathrm{P}<0.05$ was determined by the
Student criterion $(\mathrm{t})$ for unrelated samples. The indicators are presented in the form $\mathrm{x} \pm \mathrm{m}$ in the tables, in the figures - in the form $\mathrm{x} \pm \mathrm{SD}$. Correlations between the obtained indices were determined using the Pearson parametric criterion (r).

\section{Results}

Group I included 19 patients (64.2 \pm 17.9 mo on average), and Group II -30 patients (74.3 \pm 11.4 mo on average). According to age and anthropometric indicators, patients of groups I and II had no significant differences (Table 2).

\section{Table 2}

Age and anthropometric indices $(\mathrm{M} \pm \mathrm{m})$

\begin{tabular}{lccc}
\hline \multicolumn{1}{c}{ Index } & Group I $(\mathrm{PI}>1.3, \mathrm{n}=19)$ & Group II $(\mathrm{PI}<1.3, \mathrm{n}=30)$ & $\mathrm{P}$ \\
\hline Age, $\mathrm{mo}$ & $64.2 \pm 17.9$ & $74.3 \pm 11.4$ & 0.98 \\
Height, $\mathrm{sm}$ & $110.4 \pm 9.2$ & $117.9 \pm 5.1$ & 0.52 \\
Body weight, $\mathrm{kg}$ & $25.7 \pm 5.1$ & $23.0 \pm 3.1$ & 0.26 \\
Body area, $\mathrm{m}^{2}$ & $0.86 \pm 0.12$ & $0.85 \pm 0.07$ & 0.52 \\
\hline
\end{tabular}

No reliable differences were determined over a comparison of the parameters of HR, blood pressure, cardiac output, pre- and post-loading, oxygen saturation and oxygen debit.The hemodynamics in patients of the examined groups can be defined as hypovolemia compensated by a moderate tachycardia, due to which normal cardiac output and blood

\begin{tabular}{|c|c|c|c|}
\hline Index & Group I(PI $>1.3, \mathrm{n}=19)$ & Group II $(\mathrm{PI}<1.3, \mathrm{n}=30)$ & $\mathrm{P}$ \\
\hline HR, per min & $116.0 \pm 8.1$ & $125.4 \pm 5.8$ & 0.28 \\
\hline $\mathrm{SBP}, \mathrm{mm} \mathrm{Hg}$ & $100.2 \pm 2.8$ & $98.9 \pm 2.4$ & 0.20 \\
\hline $\mathrm{DBP}, \mathrm{mm} \mathrm{Hg}$ & $56.8 \pm 2.3$ & $59.6 \pm 2.0$ & 0.93 \\
\hline $\mathrm{MBP}, \mathrm{mm} \mathrm{Hg}$ & $71.3 \pm 2.3$ & $72.7 \pm 2.1$ & 0.69 \\
\hline EDD, sm & $2.99 \pm 0.20$ & $3.19 \pm 0.13$ & 0.67 \\
\hline ESD, sm & $1.82 \pm 0.14$ & $2.04 \pm 0.10$ & 0.21 \\
\hline $\mathrm{EDV}, \mathrm{ml}$ & $39.5 \pm 6.5$ & $43.6 \pm 4.1$ & 0.92 \\
\hline $\mathrm{EDV}, \mathrm{ml}$ & $12.0 \pm 2.3$ & $15.1 \pm 2.0$ & 0.84 \\
\hline IEDV, $\mathrm{ml} / \mathrm{m}^{2}$ & $44.0 \pm 2.0$ & $51.4 \pm 2.6$ & 0.12 \\
\hline $\mathrm{SV}, \mathrm{ml}$ & $27.6 \pm 4.5$ & $28.5 \pm 2.7$ & 0.74 \\
\hline $\mathrm{SI}, \mathrm{ml} / \mathrm{m}^{2}$ & $30.5 \pm 1.8$ & $34.0 \pm 2.2$ & 0.64 \\
\hline $\mathrm{CO}, 1 / \mathrm{min}$ & $2.71 \pm 0.36$ & $3.28 \pm 0.28$ & 0.50 \\
\hline $\mathrm{CI}, 1 / \mathrm{min} / \mathrm{m}^{2}$ & $3.50 \pm 0.32$ & $4.20 \pm 0.37$ & 0.50 \\
\hline $\mathrm{EF}, \%$ & $0.69 \pm 0.03$ & $0.66 \pm 0.02$ & 0.18 \\
\hline ISVR, $\operatorname{din} \times \mathrm{S}^{\times} \times \mathrm{Sm}^{-5} \times \mathrm{m}^{2}$ & $1900 \pm 199$ & $1547 \pm 110$ & 0.08 \\
\hline $\mathrm{SaO}_{2}, \%$ & $97.9 \pm 0.3$ & $97.1 \pm 0.7$ & 0.32 \\
\hline $\mathrm{DO}_{2}, \mathrm{ml} / \mathrm{min} / \mathrm{m}^{2}$ & $487 \pm 42$ & $602 \pm 44$ & 0.32 \\
\hline
\end{tabular}
pressure were provided. However, it is worth noting that in Group I the afterload index (ISVR) equaled 1900.0 $\pm 198.7 \mathrm{dyn} \times \mathrm{s} \times \mathrm{cm}^{-5} \times \mathrm{m}^{2}$. This figure exceeds the upper limit of standards $\left(1600 \mathrm{dyn} \times \mathrm{s} \times \mathrm{cm}^{-5} \times \mathrm{m}^{2}\right)$, and therefore, one can express the opinion that vasoconstriction was observed in this group. The vasoconstriction was either compensatory in nature, or it was an element of support for cerebral perfusion under conditions of a statistically unreliable tendency to lower CI in Group I $\left(3.50 \pm 0.32 \mathrm{l} / \mathrm{min} / \mathrm{m}^{2}\right)$ compared with Group II $\left(4.20 \pm 0.37 \mathrm{1} / \mathrm{min} / \mathrm{m}^{2}\right.$, $\mathrm{P}=0.50)($ Table 3$)$.

Table 3

Indices of hemodynamic and oxygen transport $(\mathrm{M} \pm \mathrm{m})$

According to the content of the electrolytes, haemoglobin, protein, glucose, lactate and urea, no significant differences between groups I and II were observed. Thus, pathological changes in the parameters that can affect the level of osmolality and, accordingly, the intracranial pressure in the examined groups were not noted. However, the level of creatinine in Group II was significantly higher than in Group I, although it remained within the normal range (up to $110 \mu \mathrm{mol} / \mathrm{L}$ ). Both groups were characterized by a slight reduction in hemoglobin and an increase in the content of lactate (the norm level up to $2.4 \mathrm{mmol} / \mathrm{L}$ ) (Table 4).

Unlike central hemodynamic parameters, cerebral hemodynamic indexes (excluding maximal systolic blood flow velocities) between groups I and II had significant differences. Thus, in Group I, compared with Group II, the minimal (diastolic) velocity of the flow in the right and left MCA was significantly lower (Table 5).

Compared with the control group $\mathrm{V}_{\max }(86.1 \pm 1.9 \mathrm{~cm} / \mathrm{s})$, no significant differences were observed between groups I and II $(\mathrm{P}>0.05)$. 
Indicators of RI and PI of MCA in patients of Group I were significantly higher than in patients of Group II. Compared to normal values of RI $(0.68 \pm 0.7)$ and RI $(0.47 \pm 0.4)$, which are given in various sources, their values in groups I and II also were significantly higher $(\mathrm{P}<0.001)$. Disorders of consciousness (by the Glasgow scale) were much more pronounced in Group I and equalled $7.8 \pm 0.6$ points (Table 5). The cerebral perfusion pressure (eCPP) in Group I was significantly lower $(29.5 \pm 1.3 \mathrm{~mm} \mathrm{Hg})$ than in Group II $(41.6 \pm 1.7 \mathrm{~mm} \mathrm{Hg})($ Fig. 1). It is interesting to note that in the examined patients a direct moderately strong correlation between $\mathrm{SBP}$ and $\mathrm{eCPP}(\mathrm{r}=0.65, \mathrm{P}<0.05)$ was observed.

Table 4

Biochemical indexes $(\mathrm{M} \pm \mathrm{m})$

\begin{tabular}{lccc}
\hline \multicolumn{1}{c}{ Index } & Group I $(\mathrm{PI}>1.3, \mathrm{n}=19)$ & Group II $(\mathrm{PI}<1.3, \mathrm{n}=30)$ & $\mathrm{P}$ \\
\hline $\mathrm{Na}^{+}, \mathrm{mmol} / \mathrm{L}$ & $142.7 \pm 2.5$ & $139.8 \pm 1.4$ & 0.95 \\
$\mathrm{~K}^{+}, \mathrm{mmol} / \mathrm{L}$ & $3.65 \pm 0.14$ & $3.88 \pm 0.12$ & 0.94 \\
$\mathrm{Ca}^{+}, \mathrm{mmol} / \mathrm{L}$ & $1.25 \pm 0.08$ & $1.17 \pm 0.07$ & 0.34 \\
$\mathrm{Cl}, \mathrm{mmol} / \mathrm{L}$ & $103.7 \pm 2.2$ & $100.8 \pm 1.0$ & 0.31 \\
Hemoglobin, $\mathrm{g} / \mathrm{L}$ & $111.4 \pm 5.7$ & $115.1 \pm 3.7$ & 0.86 \\
Hematocrit & $0.31 \pm 0.01$ & $0.33 \pm 0.01$ & 0.51 \\
Total protein, $\mathrm{g} / \mathrm{L}$ & $56.7 \pm 2.2$ & $60.9 \pm 1.7$ & 0.02 \\
Creatinine, $\mathrm{mkmo} / \mathrm{L}$ & $85.5 \pm 4.2$ & $101.1 \pm 5.2$ & 0.09 \\
Urea, $\mathrm{mmol} / \mathrm{L}$ & $4.75 \pm 0.46$ & $6.18 \pm 0.46$ & 0.20 \\
Lactate, $\mathrm{mmol} / \mathrm{L}$ & $3.73 \pm 1.07$ & $2.72 \pm 0.43$ & 0.16 \\
Glucose, $\mathrm{mmol} / \mathrm{L}$ & $6.0 \pm 0.5$ & $5.9 \pm 0.3$ & 0.92 \\
\hline
\end{tabular}

\section{Table 5}

Indicators of cerebral homeostasis $(\mathrm{M} \pm \mathrm{m})$

\begin{tabular}{lccc}
\hline \multicolumn{1}{c}{ Index } & Group I $(\mathrm{PI}>1.3, \mathrm{n}=19)$ & $\begin{array}{c}\text { Group II }(\mathrm{PI}<1.3, \mathrm{n}= \\
30)\end{array}$ & $\mathrm{P}$ \\
\hline Vmax RMCA, sm/s & $97.7 \pm 6.0$ & $113.9 \pm 8.9$ & 0.570 \\
Vmin RMCA, sm/s & $25.5 \pm 2.8$ & $48.0 \pm 4.6$ & 0.004 \\
RI RMCA & $0.74 \pm 0.02$ & $0.59 \pm 0.01$ & $<0.0001$ \\
PI RMCA & $1.50 \pm 0.07$ & $0.97 \pm 0.03$ & $<0.0001$ \\
Vmax LMCA, sm/s & $96.8 \pm 6.9$ & $116.0 \pm 8.4$ & 0.591 \\
Vmin LMCA, sm/s & $21.2 \pm 1.9$ & $48.2 \pm 4.1$ & $<0.0001$ \\
RI LMCA & $0.78 \pm 0.01$ & $0.59 \pm 0.01$ & $<0.0001$ \\
PI LMCA & $1.65 \pm 0.05$ & $0.98 \pm 0.03$ & $<0.0001$ \\
eCPP, mmHg & $29.5 \pm 1.3$ & $41.6 \pm 1.7$ & $<0.0005$ \\
RAP & $1.55 \pm 0.10$ & $1.24 \pm 0.10$ & 0.111 \\
ZFP, mmHg & $41.8 \pm 2.3$ & $31.1 \pm 2.2$ & 0.005 \\
CFle, sm/s ${ }^{-1}$ & $40.6 \pm 2.5$ & $73.0 \pm 4.1$ & $<0.0001$ \\
Scale Glasgow, point & $7.8 \pm 0.6$ & $9.6 \pm 0.5$ & 0.040 \\
\hline
\end{tabular}

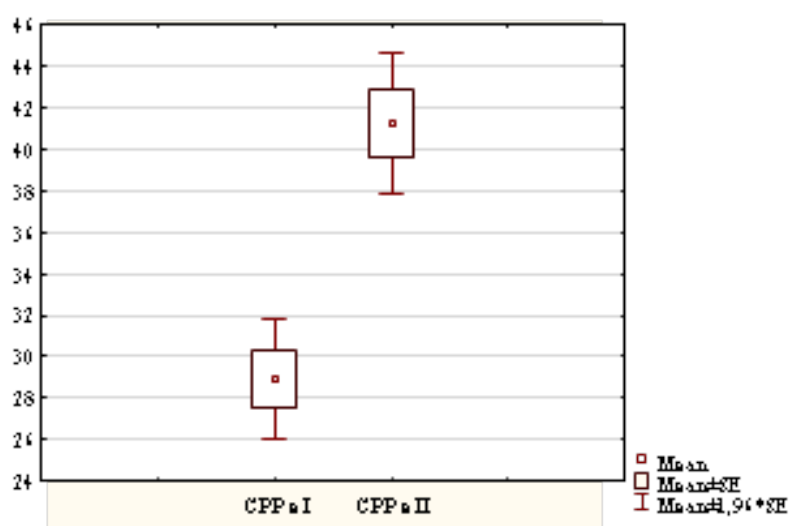

Fig. 1. Cerebral perfusions pressure in groups I and II

In the absence of significant differences in the MBP score between the examined groups, the difference in $\mathrm{CCPP}$ was due to the significant difference between eICP in Groups I and II $-34.6 \pm 1.4 \mathrm{~mm} \mathrm{Hg}$ and $27.6 \pm 0.89 \mathrm{~mm} \mathrm{Hg}$ respectively. Thus, both groups were characterized by the presence of critical intracranial hypertension (according to formula Edouard et al.) (Fig. 2).

The RAP indicator, which reflects the existence of a compensatory reserve for mitigating ICP fluctuations, did not have any significant differences between groups $(P=0.111)$. Thus, we can express the view that in Group II, despite the lower degree of intracranial hypertension and hypoperfusion, the compensation reserve was also reduced and there was a risk of ICP's critical growth in certain, unfavourable conditions. Zeroflow pressure (ZFP) in Group 1 was significantly higher than in Group 2 $(\mathrm{P}=0.005)$, so the termination of the arterial cerebral blood flow in Group 1 would occur with MBP about $42 \mathrm{~mm} \mathrm{Hg}$, and in Group 2 $31 \mathrm{~mm} \mathrm{Hg}$. The cerebral flow index CFle in Group I was almost twice lower than in the Group II $(\mathrm{P}<0.0001)$ (Table 5). This indicator also had a moderate direct correlation with $\mathrm{CI}(\mathrm{r}=0.50, \mathrm{P}<0.05)$. In our opinion, the direct correlation between the parameters of cardiac output and cerebral flow can be explained by the loss of autoregulation in some patients, which makes maintaining cerebral circulation directly dependent on cardiac output.

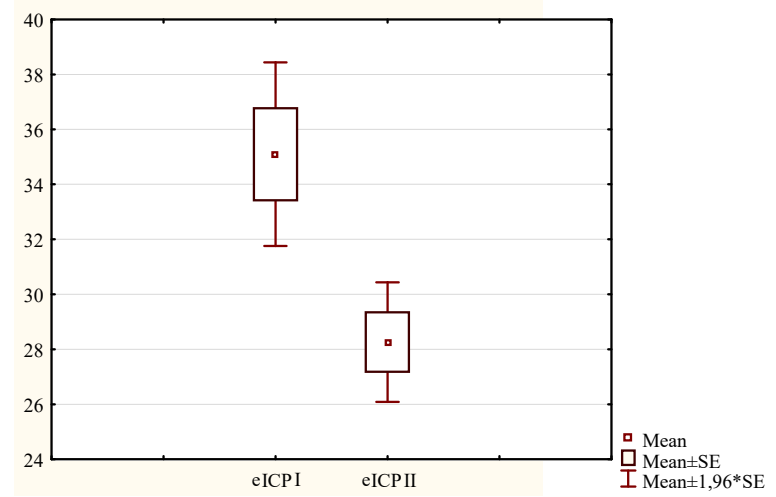

Fig. 2. Intracranial pressure in groups I and II

Regardless of the formula used to determine ICP, groups I and II exhibited a highly reliable difference between its indices. However, it should be emphasyzed that in Group I (with PI more than 1.3, which should correspond to the presence of intracranial hypertension), the ICP established by the Bellner et al formula corresponds to the upper limit of normal values (Table 6).

Table 6

Indicators of intracranial pressure obtained by different formulae $(\mathrm{M} \pm \mathrm{m})$

\begin{tabular}{lccc}
\hline \multicolumn{1}{c}{ Index } & Group I $(\mathrm{PI}>1.3, \mathrm{n}=19)$ & Group II $(\mathrm{PI}<1.3, \mathrm{n}=30)$ & $\mathrm{P}$ \\
\hline eICP, $\mathrm{mmHg}$ & $34.62 \pm 1.40$ & $27.61 \pm 0.89$ & 0.000098 \\
eICP $(\mathrm{K}), \mathrm{mmHg}$ & $20.83 \pm 1.77$ & $14.81 \pm 0.67$ & 0.000705 \\
eICP $(\mathrm{B}), \mathrm{mmHg}$ & $15.75 \pm 1.03$ & $9.35 \pm 0.35$ & 0.000001 \\
\hline
\end{tabular}

The ICP determined using the method of Kligenchöfer et al. eICP (K) did not have a significant difference from the ICP indicator determined using the formula of by Bellner et al. eICP (B) in Group I $(\mathrm{P}=0.03)$. The eICP parameter in group I significantly differed from $\mathrm{eICP}(\mathrm{B})(\mathrm{P}=0.05)$ and did not have a significant difference with $\operatorname{eICP}(\mathrm{K})(\mathrm{P}=0.79)$ (Fig. 3).

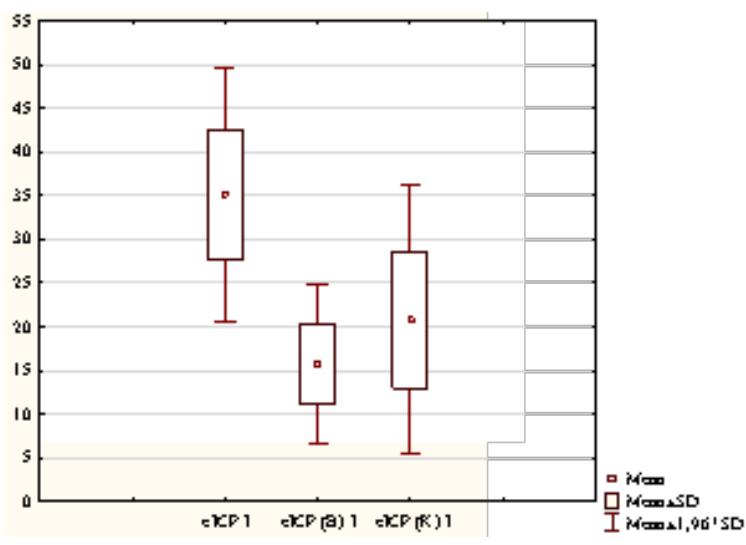

Fig. 3. Intracranial pressure in group I, which is determined by the formulae of Edouard et al. (eICP I), Bellner et al. (eICP (B)) I and Klingelhofer et al. (eICP (K))

Thus, the ICP indicators according to the formulae of Edouard et al. and Kligenchöfer et al. give similar results that correspond to the presence of intracranial hypertension, in contrast to the ICP indicator determined using the method of Bellner et al. In Group II (with PI less than 1.3, 
which should correspond to the absence of intracranial hypertension) ICP, determined using the method of Bellner et al. and Kligenchöfer et al., corresponded to normal values. ICP determined by the method of Edouard et al., corresponded to intracranial hypertension $-27.6 \pm 0.89 \mathrm{~mm} \mathrm{Hg}$ (Table 6). In Group II the ICP, determined using the method of Kligenchöfer et al. eICP $(\mathrm{K})$, was significantly higher than the ICP, calculated by Bellner et al. eICP $(\mathrm{B})$ in Group II $(\mathrm{P}=0.001)$. The eICP in Group II significantly differed from eICP $(\mathrm{B})(\mathrm{P}<0.001)$ and eICP $(\mathrm{K})(\mathrm{P}=$ 0.007). So, in the group of patients with PI less than 1.3, ICP indices by Bellner et al. and Kligenchöfer et al. give results that are consistent with the absence of intracranial hypertension, as opposed to the ICP determined by Edouard et al, which indicates an intracranial hypertension of more than $20 \mathrm{~mm} \mathrm{Hg}$.

Thus, the determining of ICP by the Edouard et al. formula probably, can lead to hyperdiagnosis, but by the Bellner et al. formula - to the hypodiagnosis of intracranial hypertension. So, the most adequate formula for determining the ICP in children with neuroinfection is, in our opinion, the Kligenchöfer et al. formula, and the least suitable formula is the Bellner et al. formula (Fig. 4). The likely cause of significant differences in intracranial pressure and hypodiagnosis of intracranial hypertension using the equation of Bellner et al. can be explained by the fact that it was obtained by regression in adults with craniocerebral trauma. That is why, these results depend on the calculated coefficients of regression, which do not reflect the characteristics of the children we examined. However, the results we have obtained should not be considered as evidence of the inapplicability of the Bellner et al. formula, which was obtained under the control of intracranial pressure by the method of invasive monitoring with the use of intraventricular systems.

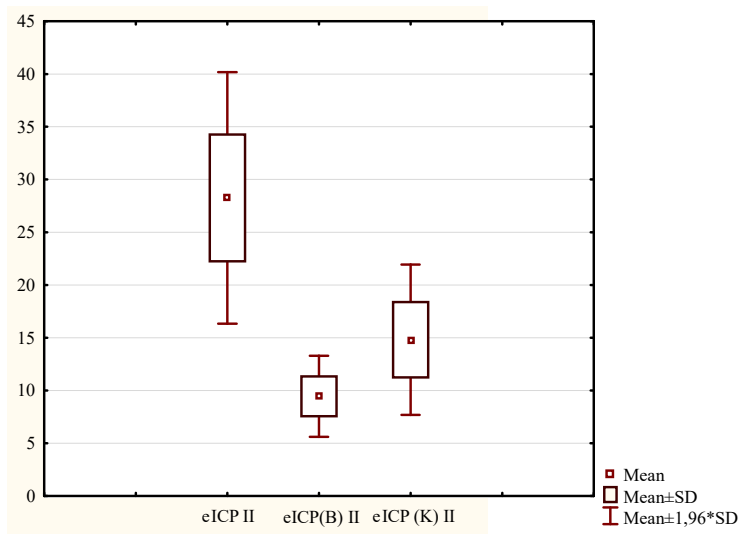

Fig. 4. Intracranial pressure in Group II is determined by formulae of Edouard et al. (eICP II), Bellner et al. (eICP (B) II) and Klingelhofer et al. (eICP (K) II)

Clinical case. Boy F-v T., 6 months, body weight 7 kg, was hospitalized to the Department of Anaesthesiology and Critical Care in April 16, 2015 with a state of clonical tonic convulsions, which lasted for several hours. Without consciousness, Glasgow score was 6 points. HR 104 for $1 \mathrm{~min}, \mathrm{MBP} 62 \mathrm{~mm} \mathrm{Hg}$. Positive symptom of "pale spot". The convulsions were stopped by the diazepam injection, vital functions were monitored, central venous access was provided. After anesthesia with thiopental sodium, endotracheal intubation was performed, respiratory support was started with pressure control in the normo-ventilation mode $\left(\mathrm{EtCO}_{2}\right.$ $40 \mathrm{mmHg}$ ). Leukocytosis $30.2 \cdot 10^{9} / 1$. Duplex scans for blood flow in MCA were carried out. $V_{\max }$ RMCA $97 \mathrm{sm} / \mathrm{s}, V_{\min }$ RMCA $20 \mathrm{sm} / \mathrm{s}$, PI RMCA 1.75, RI RMCA 0.79, $\mathrm{V}_{\max }$ LMCA $71 \mathrm{sm} / \mathrm{s}, \mathrm{V}_{\min }$ LMCA $21 \mathrm{sm} / \mathrm{s}$, PI LMCA 1.35. RI LMCA 0.71. eCPP RMCA $25.5 \mathrm{mmHg}$, eICP RMCA 36.5 mm Hg, eICP (B) RMCA $17.1 \mathrm{~mm} \mathrm{Hg}$, eICP (K) RMCA $19.0 \mathrm{~mm} \mathrm{Hg}$, CFIe RMCA $32.1 \mathrm{sm} / \mathrm{s}$, ZFP RMCA $36.8 \mathrm{~mm} \mathrm{Hg}$. The diameter of the right orbital nerve was $5.1 \mathrm{~mm}$ (the norm is less than 4.5). Thus, a critical intracranial hypertension, hypoperfusion of the brain was diagnosed. After the onset of infusion of sympathomimetics (dopamine $10 \mu \mathrm{g} / \mathrm{kg} / \mathrm{min}$ ) and osmodiuretics, a repeat study showed an increase in MBP up to $71 \mathrm{~mm} \mathrm{Hg}$, eCPR RMSA up to $58 \mathrm{~mm} \mathrm{Hg}$, a decrease in eICP RMSA to $12.5 \mathrm{~mm} \mathrm{Hg}$, reduction of the diameter of the right optic nerve to $3.9 \mathrm{~mm}$. Within a day consciousness was resto- red, respiratory support was discontinued. During magnetic resonance tomography, bilateral subdural empyemas were been identified. The following treratment was carried out in the conditions of neurosurgic department.

\section{Discussion}

Support for cerebral perfusion pressure and intracranial pressure is the basis of modern intensive care doctrines for patients with severe craniocerebral trauma. In neuroreanimatology, quite contradictory doctrines of intensive therapy are based on the study and monitoring of indicators that determine the adequacy of brain perfusion (Kochanek et al., 2012). First of all, this concerns Rosner's doctrine, or the doctrine of maintaining CPP through mechanisms of autonomic regulation of cerebrospinal fluid flow and ICP control doctrine, as well as its type - the Lund University doctrine, which is based on limiting intracranial pressure and perfusion based on the recognition of the loss of autoregulation (Krikman \& Smith). The impossibility of using invasive instrumental methods for determining the state of cerebral circulation and its autoregulation in patients with a non-surgical profile, patients with infections of the central nervous system, leads to a significant limitation of both fundamental ideas about the mechanisms of its secondary damage in this contingent of patients and the substantiation of purposeful, pathogenetically substantiated intensive therapy. It should be noted that individual studies confirm that monitoring intracranial pressure reduces the mortality of patients with meningitis (Tariq et al., 2017). Thus, non-invasive (ultrasound) methods of monitoring ICP and CPP can be the basis for an in-depth study of the features of hemodynamics and cerebrovascular disorders, cerebral perfusion, its autoregulation, the presence or absence of the phenomenon of cerebral vasospasm. In turn, understanding the characteristics of pathogenetic disorders, both in the identified cohort of patients and in individuals, gives a reason to hope for the development of the doctrine of scientifically-based neurointensive therapy in non-surgical patients in spite of copying the protocols of intensive therapy for CCT, or, even worse, routine use of some aspects of intensive care (for example, using of osmodiuretics, or hyperventilation) without feedback about the feasibility and effectiveness of these prescriptions. As Robert C. Tasker, in a letter to Crit Care Med, says: "We need to review whether therapy to control ICP - mannitol and hyperventilation benefits or potential harm (Tasker, 2014). In the Cochrane Review 2013, it was concluded that osmotic diuretics should not be prescribed to adult and pediatric patients with bacterial meningitis (Wall et al., 2013). The results obtained by us are one of the first attempts to use ultrasound dopplerographic methods for the determination of cerebral flow in children with central nervous system infections in an intensive care unit. Extremely invasive methods of control were used in close-up content work devoted to the intensive care of neuroinfections (Kumar et al., 2014; Tariq et al., 2017). At the same time, the vast majority of publications devoted to the study of cerebral flow by non-invasive ultrasound methods refer to neurosurgical patients, mostly adults (Alali et al., 2015; O'Brien et al., 2015). These studies, quite understandably, state the presence of intracranial hypertension and hypoperfusion, which are established, including noninvasive ultrasound methods. One Russian study is devoted to the dopplerographic determination of blood flow in children with neuroinfections. It concerns only a very limited contingent of patients with serous meningitis, which has a favourable course and usually does not require intensive care. Thus, these children were not in an intensive care unit and indicators of non-invasive ICP and non-invasive CPP were not identified (Rosin, 2010). We also found a publication that described only two cases of the use of doppler blood flow in the middle cerebral arteries in adults with encephalitis. In the described cases, the authors stated an increase in the pulsation index (Kargiotis et al., 2016). Somewhat larger in scale was a recent study using transcranial doppler in 20 children with infections of the CNS. Its authors proposed the hypothesis that children with infections of the CNS have abnormal cerebral blood flow, which can be a factor of complications and unfavourable neurological consequences. This single group retrospective study included children with an average age of $8.2 \pm 6.3$ years, including 12 boys and 8 girls. $55 \%$ of them had meningitis, 15 had encephalitis (15\%), 20\% had meningoencephalitis, the rest had an abscess or empyema (10\%). Transcranial 
dopplerography was performed within $4 \pm 9$ days after admission to the intensive care unit. The authors conclude that the average speed of cerebral blood flow increases in comparison with the control values through hyperemia $(n=21,60 \%)$ and vasospasm $(n=2,6 \%)$. Sequential transcranial dopplers were used to control arterial pressure. The authors of the study conclude that transcranial doppler can be used in children with CNS infections as a tool for evaluation of cerebral blood flow and consider it promising and expedient to conduct prospective studies in this direction.

Thus, available literature data indicate the expediency of determining blood flow in the mid-cerebral arteries as a method that helps to objectify the nature of pathological changes in the cranial cavity by noninvasive means. The results obtained with the Doppler ultrasound can be used to predict the course of the critical state and or adequate correction of intensive therapy. Thus, taking into account the existing deficiency of information on the state of cerebral hemo- and liquor dynamics in children with severe forms of infectious diseases of the CNS, the results obtained in our study are of great importance. We also believe that further research in this direction should be continued.

\section{Conclusions}

Noninvasive determination of cerebral perfusion pressure and intracranial pressure in children with central nervous system infections may be appropriate, since it allows correction of intensive therapy of intracranial hypertension. Transcranial duplex blood flow examination through the mid-cerebral arteries is one of the most common methods of noninvasive determination of intracranial homeostasis parameters. Data from the study show that in children with central nervous system infections accompanied by the development of disorders of consciousness and convulsive syndrome, intracranial hypertension is detected, and in the group of patients with PI more than 1.3 it reaches $34.6 \pm 1.4 \mathrm{~mm} \mathrm{Hg}$, and is accompanied by reduction of cerebral perfusion pressure to $29.5 \pm$ $1.3 \mathrm{~mm} \mathrm{Hg}$, and cerebral blood flow index to $40.6 \pm 2.5 \mathrm{~cm} / \mathrm{s}$. Thus, conditions for the development of cerebral ischemia and ischemic brain damage are created. This is a secondary mechanism of brain disorders the primary is inflammatory process in CNS. So, an increase in PI in the middle cerebral arteries of more than 1.3 is a fast and simple criterion for the presence of critical hypertension of more than $20 \mathrm{~mm} \mathrm{Hg}$ and brain hypoperfusion in children with infections of the central nervous system.

In our opinion, the determination of CPP, zero-flow pressure, cerebral blood flow index by the method of Edouard et al., and intracranial pressure by the Kligenchöfer et al. method was the most expedient, but further studies with comparative control by an invasive intracranial pressure monitoring method are necessary. The obtained data can be useful for objectifying the severity of the condition, predicting the outcomes of neuroinfections, choosing the directions of intensive care and evaluating its effectiveness.

\section{References}

Alali, A., Gomez, D., Sathya, C., Burd, R., Mainprize, T., Moulton, R., Falcone, R., de Mestral, C., \& Nathens, A. (2015). Intracranial pressure monitoring among children with severe traumatic brain injury. Journal of Neurosurgery: Pediatrics, $16,523-532$.

Asiedua, D., Leeb, K., Mills, G., \& Kaufmann, E. (2014). A review of non-invasive methods of monitoring intracranial pressure. Joumal of Neurology Research, 4, 1-6.

Becman, J., \& Tyler, K. (2012). Neuro-intensive care of patients with acute CNS infection. Neurotheraputics, 9, 124-138.

Bellner, J., Romner, B., Reinstrup, P., Kristansson, K.-A., Ryding, E., \& Brandt, L. (2004). Transcranial doppler sonography pulsatility index (PI) reflects intracranial pressure (ICP). Surgical Neurology, 62, 45-51.

Cardim, D., Robba, C., Bohdanowicz, M., Donelly, J., Cabella, B., Liu, X., Cabelera, M., Smelewski, P., Shmidt, B., \& Czosnyka, M. (2016). Prospective study on noninvasive assessment of intracranial pressure in traumatic brain-injured patients: Comparison of four methods. Journal of Neurotrauma, 33, 792-802.

Edouard, A., Vanhille, E., Le Moigno, S., Benhamou, D., \& Mazoit, J.-X. (2005). Non-invasive assessment of cerebral perfusion pressure in brain injured patients with moderate intracranial hypertension. British Journal of Anaesthesia, 94(2), 216-221.
Hon, K.-L., Tsang, Y., \& Chan, L. (2016). Outcome of encephalitis in pediatric intensive care unit. Indian Journal of Pediatrics, 83, 1098-1103.

Hovart, C., Mtaweh, H., \& Bell, M. (2016). Management of the pediatric neurocritical care patient. Seminars in Neurology, 37, 492-501.

Kargiotis, O., Safouris, A., Magoufis, G., Stamboulis, E., \& Tsivgoulis, G. (2016). Transcranial color-coded duplex in acute encephalitis: Current status and future prospects. Journal of Neuroimaging, 26(4), 377-382.

Kirkman, M., \& Smith, M. (2014). Intracranial pressure monitoring, cerebral perfusion pressure estimation, and ICP/CPP-guided therapy: A standard of care or optional extra after brain injury? British Journal of Anaesthesia, 112(1), 35-46.

Kligenchöfer, J., Conrad, B., Benecke, R., Sander, D., \& Markakis, E. (1988). Evaluation of intracranial pressure from transcranial Doppler studies in cerebral disease. Journal of Neurology, 235, 159-162.

Kochanek, P., Carney, N., Adelson, P., Ashwal, S., Bell, M., Bratton, S., Carson, S., Chesnut, R., Chajar, J., Goldstein, B., Grant, G., Kissoon, N., Peterson, K., Selden, N., Tasker, R., Tong, K., Vavilala, M., Wainwright, M., \& Warden, C. (2012). Guidelines for the acute medical management of severe traumatic brain injury in infants, children, and adolescents. Second Edition. Pediatric Critical Care Medicine, 13(1 suppl.), 1-81.

Kumar, R., Singhi, S., Singhi, P., Jayashree, M., Bansal, A., \& Bhatti, A. (2014). Randomized controlled trial comparing cerebral perfusion pressure-targeted therapy versus intracranial pressure-targeted therapy for raised intracranial pressure due to acute CNS infections in children. Critical Care Medicine, 42(8), 1775-1787.

Lan, S-Y., Lin, J.-J., Hsia, S.-H., Wang, Y.-S., Chiu Lin, K.-L., \& CHEESE Study Group (2016). Analysis of fulminant cerebral edema in acute pediatric encephalitis. Pediatrics and Neonatology, 57, 402-407.

LaRovere, K., \& O’Brien, N. (2015). Transcranial Doppler sonography in pediatric neurocritical care. A review of clinical applications and case illustrations in the pediatric intensive care unit. Journal of Ultrasound in Medicine, 34, 2121-2132.

Lindvall, P., Alhm, C., Ericsson, M., Gothefors, L., Naredi, S., \& Koskinen, L.-O. (2004). Reducing intracranial pressure may increase survival among patientes with bacterial meningitis. Clinical Infectious Diseases, 38, 384-390.

Lurie, A., \& Lurie, R. (2016). Use of transcranial Doppler for management of central nervous system infections in critically ill children. Pediatric Neurology, 65, 52-58.

Miller, J., Teasdale, G., Rowan, J., Galbraith, S. L., \& Mendelow, A. (1986). Intracranial pressure. Springer, Berlin.

Naqvi, J., Yap, K., Ahmad, G., \& Ghosh, J. (2013). Transcranial Doppler ultrasound: A review of the physical principles and major applications in critical care. International Journal of Vascular Medicine, 6, 1-13.

O’Brien, N., Maa, T., \& Reuter-Rice, K. (2015). Noninvasive screening for intracranial hypertension in children with acute, severe traumatic brain injury. Journal of Neurosurgery: Pediatrics, 16, 420-425.

Odetola, F., Tilford, J., \& Davis, M. (2006). Variation in the use of intracranialpressure monitoring and mortality in critically ill children with meningitis in the United States. Pediatrics, 117, 1893-1900.

Ogoh, S. (2008). Autonomic control of cerebral circulation: Exercise. Medicine and Science in Sports and Exercise, 40, 2046-2054.

Robba, C., Cardim, D., Sekhon, M., Budohoski, K., \& Czosnyka, M. (2018). Transcranial Doppler: A stethoscope for the brain-neurocritical care use. Review. Journal of Neuroscience Research, 96, 720-730.

Sadoughi, A., Rybinnik, I., \& Cohen, R. (2013). Mesurement and management of increased intracranial pressure. The Open Critical Care Medical Journal, 6, $56-65$.

Schmidt, M., Czosnyka, I., Gooskens, E., Piechnik, S., Matta, B., Whitfield, D., \& Pickard, J. (2001). Preliminary experience of the estimation of cerebral perfusion pressure using transcranial Doppler ultrasonography. Journal of Neurology, Neurosurgery, and Psychiatry, 70, 198-204.

Shein, S., Ferguson, N., Kochanek, P., Bayir, H., Clark, R., Fink, E., Tyler-Kabara, E., Wisniewski, S., Tian, Y., Balasubramani, G., \& Bell, M. (2016). Effectiveness of pharmacological therapies for intracranial hypertension in children with severe traumatic brain injury - Results from an automated data collection system time-synched to drug administration. Pediatric Critical Care Medicine, 17(3), 236-245

Tariq, A., Aguilar-Salinas, P., Hanel, R., Naval, N., \& Chmayssani, M. (2017) The role of ICP monitoring in meningitis. Neurosurgical Focus, 43(5), 1-7.

Tasker, R. (2014). Raised intracranial pressure during central nervous system infection: What should we do about it? Critical Care Medicine, 42(8), 1936-1938.

Varsos, G., Kolias, A., Smielewski, P., Brady, K., Varsos, V., Hutchinson, P., Pickard, J., \& Czosnyka, M. (2015). A noninvasive estimation of cerebral perfusion pressure using critical closing pressure. Journal of Nuerosurgery, 123, 638-648.

Wall, E., Ajdukiewicz, K., Heyderman, R., \& Garner, P. (2013). Osmotic therapies added to antibiotics for acute bacterial meningitis. Cochrane Database of Systematic Reviews, 3, CD008806. 